\title{
Discussion: Consolidation of clayey gouge amid permeating rock masses
}

\section{Ashutosh Trivedi PhD}

Professor and Head, Department of Civil Engineering, Delhi Technological University, Delhi, India

Tanmay Banik BEng

GET, Triune Energy Services Pvt Ltd, New Delhi, India

Tanay Sukumar BEng

Fellow, Teach for India, Green Park Extn, New Delhi, India

Naresh Kumar MTech

Associate Professor, Department of Civil Engineering, Delhi Technological University, Delhi, India

Akshay Jain BEng

Sales Officer, Indian Oil Corporation Ltd, Ranchi, Jharkhand, India

Amit Kumar BEng

Officer Trainee, Indian Oil Corporation Ltd, Vijayawada, Andhra Pradesh, India

\section{Contribution by S. K. Tewatia, A. Sridharan, Subhash Narayan Singh, K. Tewatia, A. Tewatia and S. Rath}

The original paper by Trivedi et al. (2014) presented a natural complicated shaped in situ clay idealised as a saturated rectangular body settling in a vertical direction with two-dimensional drainage in vertical and horizontal directions. Theoretical equations were derived for two-dimensional drainage using Fourier series. The discussers suggest a more general theoretical equation for threedimensional drainage when the soil is stratified in $X, Y$ and $Z$ directions.

\section{Theoretical equation for three-dimensional drainage when the soil is stratified in $X, Y$ and $Z$ directions}

The basic three-dimensional (3D) consolidation equation in Cartesian coordinates (Biot, 1941) is given as

$$
\frac{\partial u}{\partial t}=c_{x} \frac{\partial^{2} u}{\partial x^{2}}+c_{y} \frac{\partial^{2} u}{\partial y^{2}}+c_{z} \frac{\partial^{2} u}{\partial z^{2}}
$$

where $u$ is pore pressure, $t$ is time, $c_{x}, c_{y}$ and $c_{z}\left(=c_{v}\right)$ are coefficients of consolidation in the $X, Y$ and $Z$ directions, respectively.

Suppose, $L, B$ and $H$ are the length, breadth and height of a (cuboid) sample draining outwards from all the six phases and settling in $Z$ or vertical direction only. The Carillo (1942) type solution of Equation 47 is given by Tewatia (2013b) as

48. $\left(1-U_{x y z}\right)=\left(1-U_{x}\right)\left(1-U_{y}\right)\left(1-U_{z}\right)$

\section{S. K. Tewatia}

Central Soil and Materials Research Station, Government of India, New Delhi, India

\section{A. Sridharan}

Professor Emeritus, Department of Civil Engineering, Indian Institute of Science, Bangalore, India

Subhash Narayan Singh

Engineer, BSNL, Patna, India

\section{K. Tewatia}

Department of Civil Engineering, National Institute of Technology, Kurukshetra, India

\section{A. Tewatia}

Ansal Institute of Technology, GGS Indra Prasth University, Gurgaon, India S. Rath

Proctor, University of Engineering and Management, Jaipur, India Tewatia $(2010,2013 a)$ as

49.

$$
U=1-\frac{8}{\pi^{2}} \sum_{N=0}^{N=\infty} \frac{1}{(2 N+1)^{2}} \varepsilon^{-\frac{(2 N+1)^{2} \pi^{2}}{4} \lambda T}
$$

where $\lambda$ is given as

50. $\lambda=1+\frac{k_{y} H^{2}}{k_{z} B^{2}}+\frac{k_{x} H^{2}}{k_{z} L^{2}}$

and

51. $T=\frac{c_{v} t}{H^{2}}$

where $k_{x}, k_{y}$ and $k_{z}\left(=k_{v}\right)$ are the permeability of soil in the $X, Y$ and $Z$ directions, respectively. Equation 49 shows that in $3 \mathrm{D}$ consolidation, $T$ for a particular $t$ is increased by $\lambda$ times or $c_{v}$ is increased by $\lambda$ times (Tewatia, 2010, 2013a). Hence, $U$ for a particular $t$ increases. Equation 49 can be reduced to a two-dimensional (2D) or one-dimensional (1D) space by putting $k_{x}$ or $k_{y}$ or both equal to zero in Equation 50 .

From Equation 49, it can be shown (Tewatia, 1998, 2010, 2013a; Tewatia et al., 2007, 2013a, 2014) that a plot of settlement $(\delta)$ against rate of settlement $(\mathrm{d} \delta / \mathrm{d} t)$ gives Equation 52 after $60 \% U$.

52.

$$
\delta=-\frac{4 H^{2}}{\pi^{2} \lambda_{c_{v}}}\left(\frac{\mathrm{d} \delta}{\mathrm{d} t}\right)+\delta_{100}
$$


Equation 52 is the straight line equation in the form $y=m_{3 d} x+c$, where $m_{3 d}$ is the slope and $c$ is the intercept on the $y$-axis. The $\delta-(\mathrm{d} \delta /$ $\mathrm{d} t)$ plot is a straight line having a slope, $m_{3 d}=\left(4 H^{2}\right) /\left(\pi^{2} \lambda c_{v}\right)$ and intercept on $\delta$ axis, $c=\delta_{100}$. Thus, $c_{v}$ can be evaluated as

53.

$$
c_{v}=c_{z}=\frac{4 H^{2}}{\pi^{2} \lambda m_{3 d}}
$$

$$
c_{y}=\frac{k_{y}}{k_{v}} c_{v}
$$

55

$$
c_{x}=\frac{k_{x}}{k_{v}} c_{v}
$$

The $c_{x}, c_{y}, c_{z}$ and $\delta_{100}$ can be evaluated when the settlement, time and pressure at the instant of load increment are not known or the unknown pressure increases non-uniformly with settlement and time in the beginning. This is the usual case in consolidation of clayey gouge amid permeating rock masses. The space between the crack in rocks may be found to be decreasing in the field due to $1 \mathrm{D}, 2 \mathrm{D}$ or $3 \mathrm{D}$ consolidation of stratified soil in between the crack without knowing any history. Equations $52-55$ can be invoked by plotting the space between the crack against the rate of decrease of crack. For this purpose, a simple method of 3D crack monitoring can be used as suggested by Tewatia et al. (2006).

For clay that may contain some sand stream at the centre, the flow may be radial as well as vertical. This is another form of $3 \mathrm{D}$ drainage. Equation 49 in this case reduces to

56.

$$
U=1-\frac{8}{\pi^{2}} \exp \left(\frac{\pi^{2} \lambda T}{4}\right)
$$

Equation 56 is valid after $60 \% U$ (Tewatia, 2010, 2013a; Tewatia et al., 2013b), but the $\lambda$ is given as

57. $\lambda=1+\frac{32 k_{r} H^{2}}{\pi^{2} k_{v} d_{e}^{2} F_{n}}$

where

58.

$$
F_{n}=\frac{n^{2}}{n^{2}-1} \ln (n)-\frac{3 n^{2}-1}{4 n^{2}}
$$

where $k_{r}$ is the radial permeability and $n$ is the drain spacing ratio, given by

59. $n=d_{e} / d_{w}$ where $d_{e}$ is the diameter of influence (i.e. twice the effective radial drainage path) and $d_{w}$ is the diameter of the drain or sand stream.

Equation 56 also gives Equation 52 (with $\lambda$ by Equation 57) that is a straight line on the $\delta-(\mathrm{d} \delta / \mathrm{d} t)$ plot. The intercept on the $\delta$ axis is $\delta_{100}$, and $c_{v}$ can be evaluated by Equation 53 and

60.

$$
c_{r}=\frac{k_{r}}{k_{v}} c_{v}
$$

The shapes of 3D consolidation curves for various values of $\lambda$ are given by Tewatia (2013a). Here, Equations 52, 53, 57 and 60 can also be used simply by plotting the space between the crack against the rate of decrease of crack without knowing any history of settlement, time and pressure.

\section{New factor $\lambda_{c H}$}

So far, the shapes of clay draining in $3 \mathrm{D}$ to be considered have been very simple, (e.g. cuboid, cylindrical, etc.) having well-defined $L$, $B, H, d_{e}$ and $r$. But suppose the shape is conical or obliquely sliced conical; then the problem becomes more cumbersome. Moreover, the shape of the in situ clay sample can be of any type, whatever one can imagine, for example zodiac signs. To take care of this problem, a new factor $\lambda_{c H}$ is introduced here, where

61.

$$
\lambda_{c H}=\frac{\lambda c_{v}}{H^{2}}
$$

While $\lambda$ takes care of simple geometric shaped clay, $\lambda_{c H}$ takes care of complicated shaped clay samples with $3 \mathrm{D}$ drainage. The $\lambda_{c H}$ is thus the property of in situ clay lamina of definite size, shape and drainage conditions, and it can be determined in the field itself (by Equation 52 along with $\delta_{100}$ ) by observing the trend of settlement for some time without knowing any history, shape, size and drainage conditions. Once $\lambda_{c H}$ and $\delta_{100}$ are known, then other consolidation characteristics, present, past and future time-settlement data and so on can be known using Tewatia's (2010, 2013a) methods.

\section{Secondary consolidation}

If the clayey gouge consists of peat or organic soil, then secondary consolidation may occur and Terzaghi's theory cannot be used. When settlement and time are not known in the beginning of load increment, the usual $\delta$ - $\log (t)$ method of secondary consolidation available in literature fails, as the $\delta$ - $\log (t)$ graph cannot be plotted because neither $\delta$ nor $t$ is known (Tewatia et al., 2007). But as in the case of primary consolidation, $\mathrm{d} \delta / \mathrm{d} t$ can be plotted against arbitrary settlement (say the space in the direction of settlement between the crack). The magnitude of slope of the $\delta-\log (t)$ and $\delta-\log (\mathrm{d} \delta / \mathrm{d} t)$ plots is the same. The settlement and time at the beginning of load increment can be evaluated by Tewatia's (2013a) methods. 


\section{Determination of in situ stress in rock}

Earlier in the case of primary and secondary consolidations, unknown settlement and time at the beginning of consolidation were determined just by looking at the trend of settlement in the field without taking any sample in the laboratory. However, for determination of unknown pressure on clay, which is equal to the stress on walls of the rock pressing the gouge, an undisturbed sample is taken out. Its ultimate settlements are determined with increasing pressures. Then initial pressure is calculated that is equal to the one on the clay in the crack undergoing consolidation. Theory and a solved example of this method are given below.

\section{Theoretical considerations}

It is known that for a fairly good range, the $\delta-\ln \left(\sigma^{\prime}\right)$ plot is a straight line, where $\sigma^{\prime}$ is effective pressure on clay. Let the straight line portion in $\delta$ - $\ln \left(\sigma^{\prime}\right)$ plot be represented by the following equation:

62. $\delta=a \ln \left(\sigma^{\prime}\right)+b$

where $a$ is slope of the straight line and $b$ is the intercept on the $\delta$ axis. Differentiating with respect to $\sigma^{\prime}$, we get

63. $\frac{\mathrm{d} \delta}{\mathrm{d} \sigma^{\prime}}=\frac{a}{\sigma^{\prime}}$ or $\quad \sigma^{\prime}=a \frac{\mathrm{d} \sigma^{\prime}}{\mathrm{d} \delta}$

Substituting this $\sigma^{\prime}$ in Equation 62, we get

64. $\delta=a \ln \left(\frac{\mathrm{d} \sigma^{\prime}}{\mathrm{d} \delta}\right)+(b+a \ln a)$

The following inferences can be drawn from Equations 62, 63 and 64:

- Comparing Equation 62 with Equation 64: If the $\delta-\ln \left(\sigma^{\prime}\right)$ plot is a straight line, then the $\delta-\ln \left(\mathrm{d} \sigma^{\prime} / \mathrm{d} \delta\right)$ plot is also a straight line, having the same slope. The difference between the intercepts of these two on the $\delta$ axis is equal to $a \ln (a)$, and on $\ln \left(\mathrm{d} \sigma^{\prime} / \mathrm{d} \delta\right)$ axis, it is $\ln (a)$. Therefore, these two are parallel lines separated horizontally by a distance $\ln (a)$. These two will also remain parallel on $\log _{10}$ scale.

- Unknown, pressure, $\sigma^{\prime}$, can be evaluated from Equation 63 .

- However, $a$ (and hence compression index, $C_{\mathrm{c}}$ ) can be determined from the $\delta \cdot \ln \left(\mathrm{d} \sigma^{\prime} / \mathrm{d} \delta\right)$ plot without knowing the initial pressure.

\section{Solved example}

The suggested method is illustrated by a solved example below. The data have been taken from Table 10, which shows the real pressure-compression curve in the laboratory (Tewatia, 2010).

\begin{tabular}{lrrrrrr}
\hline$\sigma^{\prime}: \mathrm{kPa}$ & 20 & 50 & 100 & 200 & 400 & 800 \\
Dial gauge reading & 152 & 260 & 424 & 578 & 730 & 851
\end{tabular}

Table 10. Dial gauge readings with known initial pressure

Initial unknown pressure is (say) $20 \mathrm{kPa}$. So Table 11 has been made after subtracting $20 \mathrm{kPa}$ from all the $\sigma^{\prime}$ values.

Question: There was an unknown overburden pressure, $\sigma_{0}$, on a clayey gouge amid permeating rock. The undisturbed clay specimen was taken in the laboratory and the first dial gauge reading was fixed at 152. Furthermore, pressure increments were given, and final settlements corresponding to them were recorded, which are given in Table 10. Find the unknown overburden pressure and draw the $\delta$ - $\log \left(\sigma^{\prime}\right)$ curve. LC of dial gauge $=0.01 \mathrm{~mm}$.

Answer: In Table 12, $\mathrm{d} \sigma^{\prime} / \mathrm{d} \delta$ (Column 6) is the ratio of the difference of two subsequent pressure increments to the difference of two subsequent dial gauge readings. This ratio is taken at the average of two subsequent dial gauge readings (Column 8) and plotted on a semi- $\log _{10}$ graph as shown in Figure 6. A curve is obtained. It is seen from this graph that a perfect straight line appears by joining three middle points. The equation of this line is

65. $\delta=213 \cdot 3 \ln \left(\frac{\mathrm{d} \sigma^{\prime}}{\mathrm{d} \delta}\right)+594 \cdot 7$

Here, the slope, $a=213 \cdot 3$ on $\ln$ scale or $m=\ln (10) a=491 \cdot 3$ on $\log _{10}$ scale. A parallel line at the horizontal distance $a=213.3$ is drawn. This line corresponds to the linear portion of the $\delta-\sigma^{\prime}$ curve on the semi-log scale. The equation for this line is:

66. $\delta=213 \cdot 3 \ln \sigma^{\prime}-550 \cdot 1$

Equation 66 gives $\sigma^{\prime}=197 \cdot 3 \mathrm{kPa}$ corresponding to $\delta=578$. But in Table 11, corresponding to $\delta=578$, pressure increment $=180$. Therefore, the in situ stress $\sigma_{0}=197 \cdot 3-180=17 \cdot 3 \mathrm{kPa}$. This correction is applied to all $\sigma^{\prime}$ values in Table 12 , and final $\delta$ - $\sigma^{\prime}$ values are obtained. Now all these corrected values are plotted against $\sigma^{\prime}$

\begin{tabular}{lcc}
\hline S. No. & $\sigma^{\prime}: \mathrm{kPa}$ & Dial gauge reading \\
\hline 1 & $\sigma_{0}$ & 152 \\
2 & $\sigma_{0}+30$ & 260 \\
3 & $\sigma_{0}+80$ & 424 \\
4 & $\sigma_{0}+180$ & 578 \\
5 & $\sigma_{0}+380$ & 730 \\
6 & $\sigma_{0}+780$ & 851
\end{tabular}

Table 11. Dial gauge readings with unknown initial pressure 


\begin{tabular}{|c|c|c|c|c|c|c|c|c|c|}
\hline S. No. & $\sigma^{\prime}: \mathrm{kPa}$ & $D G R$ & $\mathrm{~d} \delta=\left(\delta_{n}-\delta_{n-1}\right)$ & $\mathrm{d} \sigma^{\prime}=\left(\sigma_{n}^{\prime}-\sigma_{n-1}^{\prime}\right)$ & $\mathrm{d} \sigma^{\prime} / \mathrm{d} \delta$ & $a\left(\mathrm{~d} \sigma^{\prime} / \mathrm{d} \delta\right)$ & $\delta=\left(\delta_{n}+\delta_{n-1}\right) / 2$ & $\begin{array}{l}\text { Calc. } \sigma^{\prime} \text { for } \\
\text { Col 3: } \mathrm{kPa}\end{array}$ & $\begin{array}{l}\text { Actual } \\
\sigma^{\prime}: \mathrm{kPa}\end{array}$ \\
\hline 1 & $\sigma_{0}$ & 152 & & & & & & $17 \cdot 3$ & 20 \\
\hline 2 & $\sigma_{0}+30$ & 260 & 108 & 30 & 0.2778 & $59 \cdot 3$ & 206 & $47 \cdot 3$ & 50 \\
\hline 3 & $\sigma_{0}+80$ & 424 & 164 & 50 & 0.3049 & $65 \cdot 1$ & 342 & $97 \cdot 3$ & 100 \\
\hline 4 & $\sigma_{0}+180$ & 578 & 154 & 100 & 0.6494 & $138 \cdot 5$ & 501 & $197 \cdot 3$ & 200 \\
\hline 5 & $\sigma_{0}+380$ & 730 & 152 & 200 & $1 \cdot 3158$ & $280 \cdot 7$ & 654 & $397 \cdot 3$ & 400 \\
\hline 6 & $\sigma_{0}+780$ & 851 & 121 & 400 & $3 \cdot 3003$ & $704 \cdot 1$ & 790 & $797 \cdot 3$ & 800 \\
\hline
\end{tabular}

Table 12. Evaluation of $\delta-\sigma^{\prime}$ data by suggested method

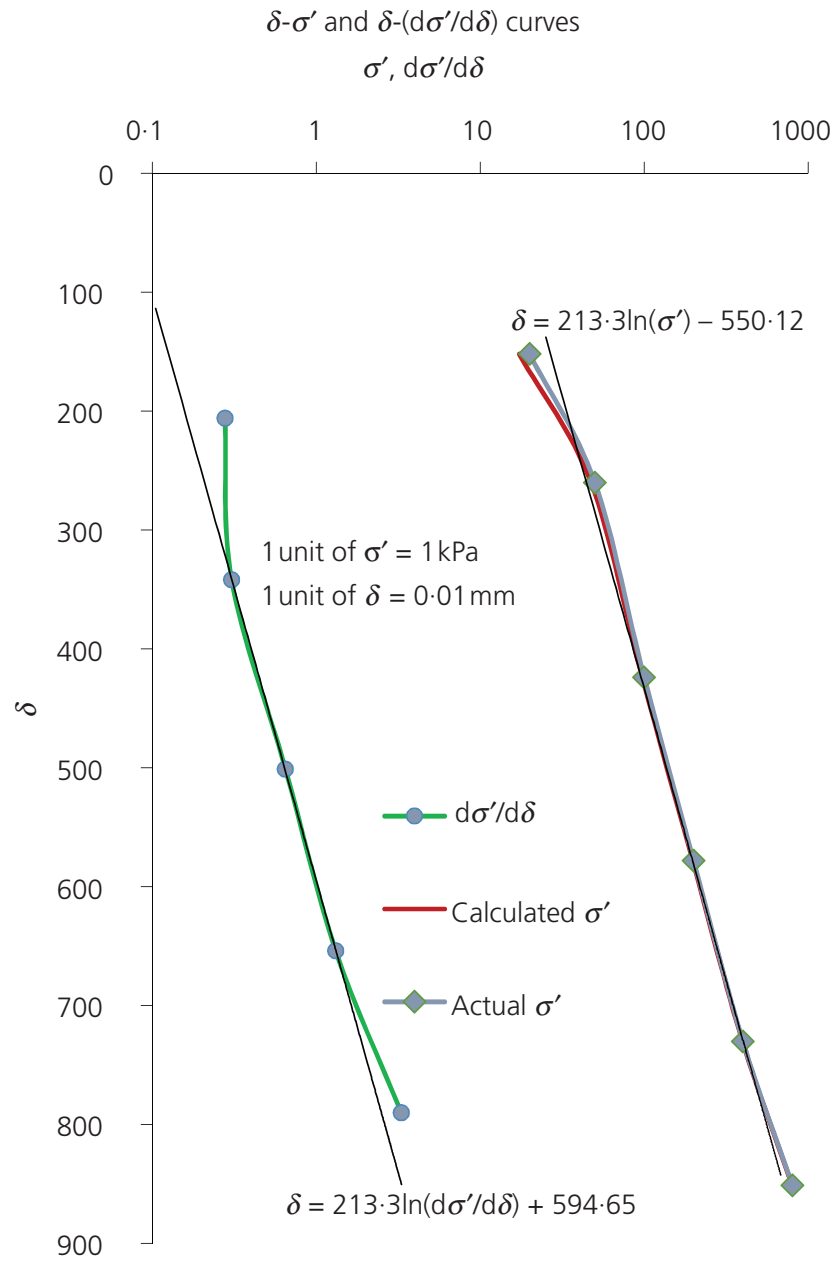

Figure 6. Evaluation of $\delta$ - $\sigma^{\prime}$ plot from $\delta$-d $\sigma^{\prime} / \mathrm{d} \delta$ plot

in Figure 6. Actual values are also plotted for comparison. It is seen that calculated and actual $\delta$ - $\sigma^{\prime}$ curves are almost the same.

Tewatia (1998, 2010, 2013a; Tewatia et al., 2007, 2013b) showed that in primary compression with whatever complicated drainage, shape and size of clay in whatever odd loadings, the $\delta$ - $(\mathrm{d} \delta / \mathrm{d} t)$ plot is a straight line in its later portion $(60-100 \% U)$. The $\lambda_{c H}$ and ultimate primary settlement $\delta_{100}$ can be evaluated from the slope of the $\delta$ - $(\mathrm{d} \delta /$ $\mathrm{d} t)$ plot without knowing the time and settlement at the instant of load increment. In secondary consolidation, the $\delta-\log (\mathrm{d} \delta / \mathrm{d} t)$ plot is a straight line having the same slope as in the case of the $\delta$ - $\log (t)$ plot, and the coefficient of secondary consolidation can be evaluated as in the case of the $\delta$ - $\log (t)$ plot. The entire $\delta$ - $t$ data of present, past and future can be generated by looking at the trend/rate of primary/ secondary settlement over some time (Tewatia, 2013a).

However, for a usual case that can be expected in permeating rock, the clay drains outwards only, and Equation 49 can be written as

67.

$$
U=1-\frac{8}{\pi^{2}} \sum_{N=0}^{N=\infty} \frac{1}{(2 N+1)^{2}} \varepsilon^{-\frac{(2 N+1)^{2} \pi^{2}}{4} \lambda_{c H} t}
$$

Comparing it with 1D Equation 68 from Terzaghi (1923),

68.

$$
U=1-\frac{8}{\pi^{2}} \sum_{N=0}^{N=\infty} \frac{1}{(2 N+1)^{2}} \varepsilon^{-\frac{(2 N+1)^{2} \pi^{2}}{4} T}
$$

it is seen that

69. $T=\lambda_{c H} t$

Therefore, it can be deduced that in usual cases of 3D consolidation of clayey gouge (of complicated shape, drainage, loadings, etc.) consolidating amid permeating rock, the shapes of settlement against rate of settlement plots in various formats are the same as in the case of $1 \mathrm{D}$ consolidation (Figure 7), only $c_{v} / H^{2}$ is increased by $\lambda$ times. These are discussed at length by Tewatia $(1998,2013 \mathrm{a})$ and Tewatia et al. (2007). However, the properties of these plots that are useful in this discussion are summarised here.

The $\delta-(\mathrm{d} t / \mathrm{d} \delta)$ plot is a straight line in the initial portion $(0-40 \% U)$, and its intercept on $\delta$ axis gives $\delta_{0}$. The $\delta$ - $(\mathrm{d} \delta / \mathrm{d} t)$ plot is a straight line in the later portion $(60-100 \% U)$, and its intercept on $\delta$ axis gives $\delta_{100}$. The $\lambda_{c H}$ can be evaluated from Equation 52 . On the 


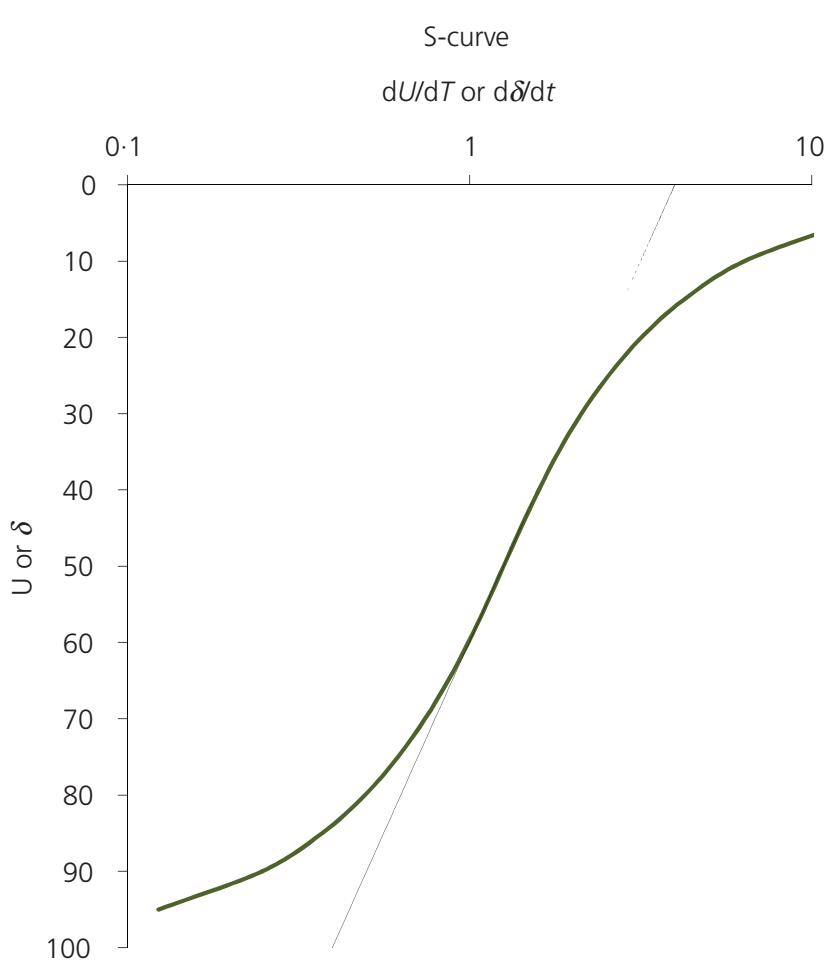

Figure 7. Shape of $U-\log _{10}(d U / d T)$ or settlement against rate of settlement (semi-log) plot

$\delta$ - $\log _{10}(\mathrm{~d} \delta / \mathrm{d} t)$ plot (S-curve, Figure 7), the initial portion is convex upwards and the latter portion is convex downwards. The slope of the S-curve in the initial portion is

70. $S_{U}=(\ln 10)\left(\delta_{U}-\delta_{0}\right)$

The slope of the S-curve in the latter portion is

71. $S_{U}=(\ln 10)\left(\delta_{100}-\delta_{U}\right)$

The slope of tangent at the point of inflection $(U=50 \%)$ gives the amount of settlement

72. $S_{50}=\delta_{100}-\delta_{0}$

By little experience, just by looking at a small portion of the S-curve in the field, an engineer can tell the approximate $U$ without any calculations. The exact $U$ can be found with the help of the equations given above.

\section{Authors' reply}

Ever since the inception of early investigations, the consolidation of clays has been a kernel of keen controversies (de Boer, 2005) and distinguished discussions (Davis and Raymond, 1965). The authors appreciate the interest of the discussers in the consolidation of clayey gouge amid permeating rock masses. The discussers have drawn some useful insights to the consolidation of clayey gouge through a set of arguments, observations and published work. The authors also take a conscious note of work on consolidation reported by the discussers. The discussers have referred to a general theoretical equation for drainage. They have reported that the consolidation of clayey gouge amid permeating rock masses in geo-environment is always in progress and settlement, time and pressure at the beginning of consolidation (or at the instant of load increment) are not well known. The discussers assume that the pressure on clay in the beginning might have been increasing non-uniformly for an unknown duration, consolidating, with complicated shape, size, drainage conditions and set stages for primary and secondary consolidation. They also have referred to a method for determining in situ stress in rock/clay, using time and settlement plots since the beginning of consolidation.

In response to the discussers' contribution, the authors propose to explain their viewpoint on the consolidation of clayey gouge frequently occurring amid permeating rock masses as follows.

\section{Exact and approximate solutions}

The authors have offered an exact numerical solution using Fourier transform to estimate consolidation, with propositions of Drichlet's problem as shown by the central line in Figure 8(a) with frequently encountered 2D drainage conditions and a rate of diffusion $\left(C^{2}\right)$ described in space (consisting of orthogonal directions namely $x$ and $z$ ) and time $(t)$ for pore pressure $(u)$.

73

$$
\frac{\partial u}{\partial t}=C^{2} \nabla^{2} u
$$

where, $\nabla^{2} u=\frac{\partial^{2} u}{\partial x^{2}}+\frac{\partial^{2} u}{\partial z^{2}}$

Most of the solutions for 2D and 3D drainage so far have referred to this quantity as corresponding to some experimental observations of $\left(C^{2}=C_{v}\right)$ in 1D oedometer, while the authors have considered an exact numerical solution based upon 2D drainage. Furthermore, most investigators, including the discussers, used a multiplier to time factor in a deviation in the consolidation estimate from the formulation of a $1 \mathrm{D}$ expression, while the authors have considered a multiplier to time factor in an exact numerical solution based upon 2D drainage.

\section{Permeability as a tensor}

The approximate solution normally captured the observed variation in the 1D, $U$ against $T v$ plots using some kind of modifiers for the time factor, say, ' $r$ ' by the authors, $\lambda$ by the discussers and other variants prevalent in the literature (Di Francesco, 2011), conceiving 0th order (by Terzaghi, 1925), first order (by authors) or second 


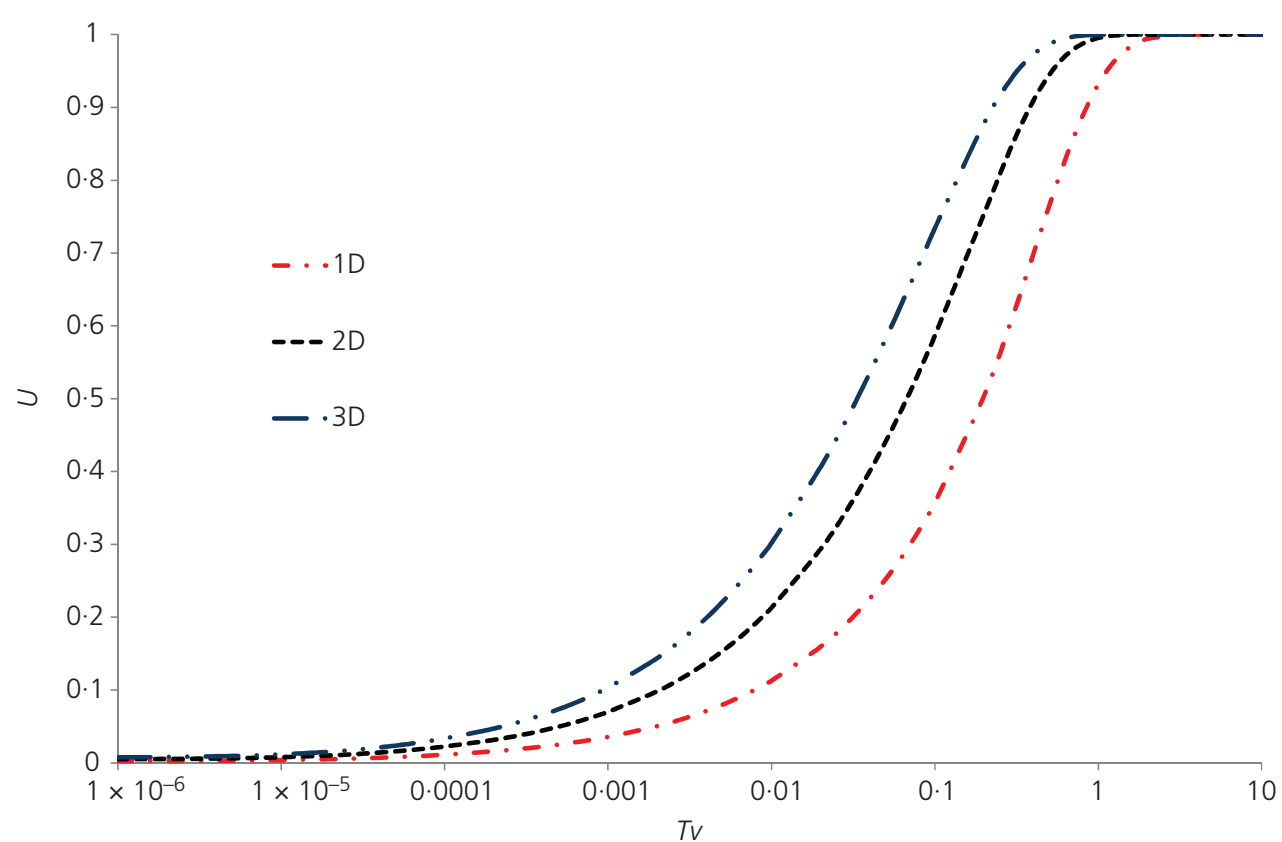

(a)

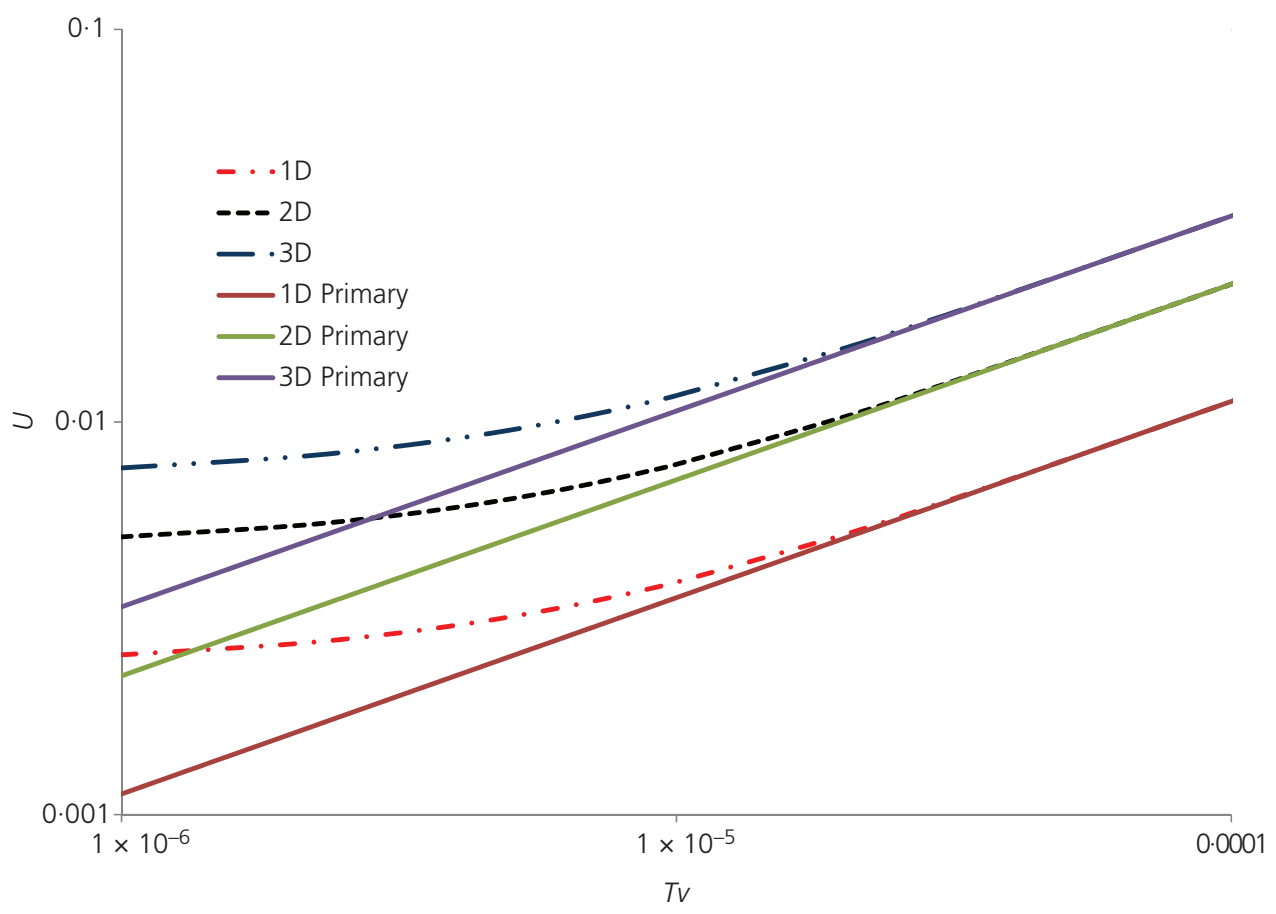

(b)

Figure 8. (a) Exact solution to the 1D, 2D and 3D consolidation (with varied initial convexities and terminal trajectories) at $T v=0 \cdot 2$, the degree of consolidation has been approximated as $U_{1 D}=50 \%, U_{2 D}=76 \%$ and $U_{3 D}=88 \%$. (b) Trajectory of primary consolidation (full lines) in relation to the initial consolidation in exact solution (dotted lines) to the 1D, 2D and 3D consolidation with reference to initial convexities. 
order tensorial variations in permeability (Bai et al., 1999; de Boer, 2000; Kubik, 1979; Kubik and Sawczuk, 1983; Liakopoulos, 1965; Oda, 1985) and deformability in the mass materials and rock masses and hence in the coefficient of consolidation $\left(C^{2}=C_{v}\right)$. As such, the values of surface permeability (as scalar) amid rock masses may also be experimentally obtained and simulated (Singh et al., 2013).
The authors have provided the values of ' $r$ ' with reference to the convexities in the exact solution for the $2 \mathrm{D}$ case extended to $1 \mathrm{D}$ and $3 \mathrm{D}$ problems [see Tables 13 to 17 in the context of the exact and approximate solutions from $1 \mathrm{D}$ to $2 \mathrm{D}$ and $3 \mathrm{D}$ solutions and from $2 \mathrm{D}$ to $1 \mathrm{D}$ and $3 \mathrm{D}$ (as variant $r \rightarrow 0,1$ and 2)]. Presumably, the discussers have also conceived the values of $\lambda$ with reference to the

\begin{tabular}{lc}
\hline $\begin{array}{l}\text { Drainage } \\
\text { condition }\end{array}$ & Exact solution for $U_{a v}$ \\
\hline $1 \mathrm{D}^{\mathrm{a}}$ & $1-\sum_{k=0}^{\infty} \frac{8}{m^{2} \pi^{2}} \exp \left[-T_{v} \frac{m^{2} \pi^{2}}{4}\right]$ \\
$2 \mathrm{D}^{\mathrm{b}}$ & $1-\sum_{k=0}^{\infty} \sum_{l=0}^{\infty} \frac{64}{m^{2} n^{2}\left(\pi^{2}\right)^{2}} \exp \left[-T_{v}\left(\frac{m^{2} \pi^{2}}{4}+r \frac{n^{2} \pi^{2}}{4}\right)\right]$ \\
$3 \mathrm{D}^{c}$ & $1-\sum_{k=0}^{\infty} \sum_{l=0}^{\infty} \sum_{j=0}^{\infty} \frac{512}{m^{2} n^{2} p^{2}\left(\pi^{2}\right)^{3}} \exp \left[-T_{v}\left(\frac{m^{2} \pi^{2}}{4}+r x \frac{n^{2} \pi^{2}}{4}+r y \frac{p^{2} \pi^{2}}{4}\right)\right]$
\end{tabular}

where $m=2 k+1, n=2 l+1, p=2 j+1$, while $k, l, j \in N$

for exact 2D case, $r=1$ and for exact $3 \mathrm{D}$ case, $r_{x}=r_{y}=1$.

a Terzaghi (1925).

b, c Authors' solution.

Table 13. Exact solution for consolidation of clayey gouge for varying drainage conditions

\begin{tabular}{|c|c|c|c|c|c|}
\hline $\begin{array}{l}\text { Dominant } \\
\text { drainage } \\
\text { condition }\end{array}$ & $\begin{array}{c}\text { Frequency of } \\
\text { occurrence } \\
\text { amid rock } \\
\text { masses }\end{array}$ & $r=r x, r y^{a}$ & $r^{\mathrm{a}}$ & $\lambda^{\mathrm{b}}$ & $C_{v} / H_{z}^{2}$ vs $C_{h} / L_{x}^{2} ; C_{h} / L_{y}^{2}$ \\
\hline $1 \mathrm{D}$ & $\begin{array}{c}\text { Less } \\
\text { frequent }\end{array}$ & $r x=r y=0$ & $r=0$ & 1 & $\begin{array}{l}C_{v} / H_{z}^{2} \gg> \\
C_{h} / L_{x}^{2} ; C_{h} / L_{y}^{2}\end{array}$ \\
\hline $2 \mathrm{D}$ & $\begin{array}{c}\text { More } \\
\text { frequent }\end{array}$ & $\begin{array}{c}r x=r \\
r y=0 \\
\text { or } \\
r y=r \\
r x=0\end{array}$ & $r=1$ & $\begin{array}{l}1+r x \\
\text { or } \\
1+r y\end{array}$ & $\begin{array}{c}C_{h} / L_{x}^{2} \gg C_{h} / L_{y}^{2} \\
\text { or } \\
C_{h} / L_{y}^{2} \gg C_{h} / L_{x}^{2}\end{array}$ \\
\hline $3 D$ & $\begin{array}{l}\text { Less } \\
\text { frequent }\end{array}$ & $\begin{array}{l}r x=r y=1 \\
2 H z=2 L x \\
2 L x=2 L y .\end{array}$ & $r=2$ & $1+r x+r y$ & $C_{v} / H_{z}^{2}=C_{h} / L_{x}^{2}=C_{h} / L_{y}^{2}$ \\
\hline
\end{tabular}

$r_{x}=\frac{C_{h x}}{C_{v z}} \frac{(2 H z)^{2}}{(2 L x)^{2}}, r_{y}=\frac{C_{h y}}{C_{v z}} \frac{(2 H z)^{2}}{(2 L y)^{2}}$

${ }^{a}$ Authors' proposal, b Discussers' proposal.

Table 14. Comparison of rock mass characteristic parameters for approximate solution to consolidation of clayey gouge amid permeating rock masses 


\begin{tabular}{|c|c|c|}
\hline $1 \mathrm{D}$ & $C_{z} \frac{\partial^{2} u}{\partial z^{2}}=\frac{\partial u}{\partial t}$ & $U a v=1-(1-U z)^{a}$ \\
\hline $2 \mathrm{D}$ & $C_{x} \frac{\partial^{2} u}{\partial x^{2}}+C_{z} \frac{\partial^{2} u}{\partial z^{2}}=\frac{\partial u}{\partial t}$ & $U a v=1-(1-U x)(1-U z)^{b, c}$ \\
\hline $3 D$ & $C_{x} \frac{\partial^{2} u}{\partial x^{2}}+C_{y} \frac{\partial^{2} u}{\partial y^{2}}+C_{z} \frac{\partial^{2} u}{\partial z^{2}}=\frac{\partial u}{\partial t}$ & Uav $=1-(1-U x)(1-U y)(1-U z)^{c}$ \\
\hline
\end{tabular}

aTerzaghi (1925), b Scott (1963), c Newman (1931).

Table 15. Initial valued problem and self-similar solutions for consolidation of clayey gouge

Drainage

$$
\begin{gathered}
1-\sum_{k=0}^{\infty} \sum_{l=0}^{\infty} \frac{64}{\left(m n \pi^{2}\right)^{2}} \exp \left[-T_{v} \frac{m^{2} \pi^{2}}{4}\right] \\
1-\sum_{k=0}^{\infty} \sum_{l=0}^{\infty} \frac{64}{\left(m n \pi^{2}\right)^{2}} \exp \left[-T_{v}\left(r \frac{n^{2} \pi^{2}}{4}+\frac{m^{2} \pi^{2}}{4}\right)\right]
\end{gathered}
$$$$
1-\sum_{k=0}^{\infty} \frac{8}{m^{2} \pi^{2}} \exp \left[-T_{v} \frac{m^{2} \pi^{2}}{4}\right]
$$

$2 \mathrm{D}$

aAuthors' solution based upon Drichlet's problem.

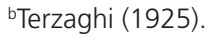

Table 16. Solution for consolidation of clayey gouge amid permeating rock masses with varied initial convexities

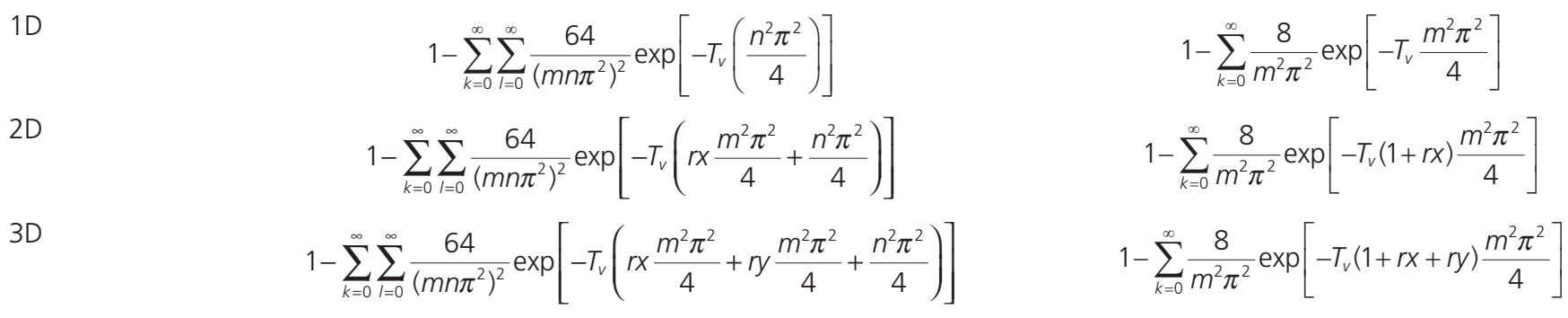

a Authors' solution based upon 2D convexities.

b Authors' approximation based upon 1D convexities.

${ }^{\text {b }}$ Discussers' approximation as $\lambda=1+r x+r y$.

Table 17. Solution for consolidation of clayey gouge with convexities of $1 \mathrm{D}$ and $2 \mathrm{D}$ drainage 
convexities in exact solution as the $1 \mathrm{D}$ case extended to $2 \mathrm{D}$ and $3 \mathrm{D}$ problems.

It is understood that the initial consolidation (initial separations that are overtly unknown as has been rightly pointed out by the discussers), in fact, determines the terminal trajectory of the $U$ against $T v$ plots (Figures 8(a) and 8(b)). The isometric distribution of $U$ in X-Z space at $T v=0.2$ for $r=0$ and 1 is shown in Figures 9(a) and 9 (b), respectively.

Since anisotropy is distributive in space as per Drichlet's problem, the authors have proposed approximate expressions based upon

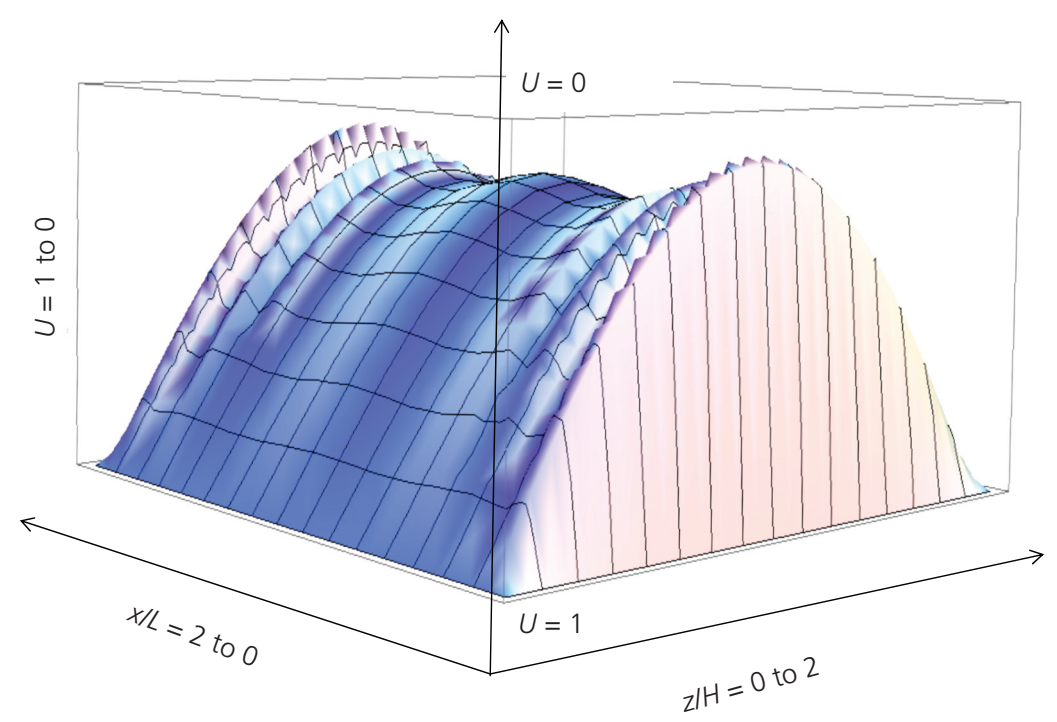

(a)

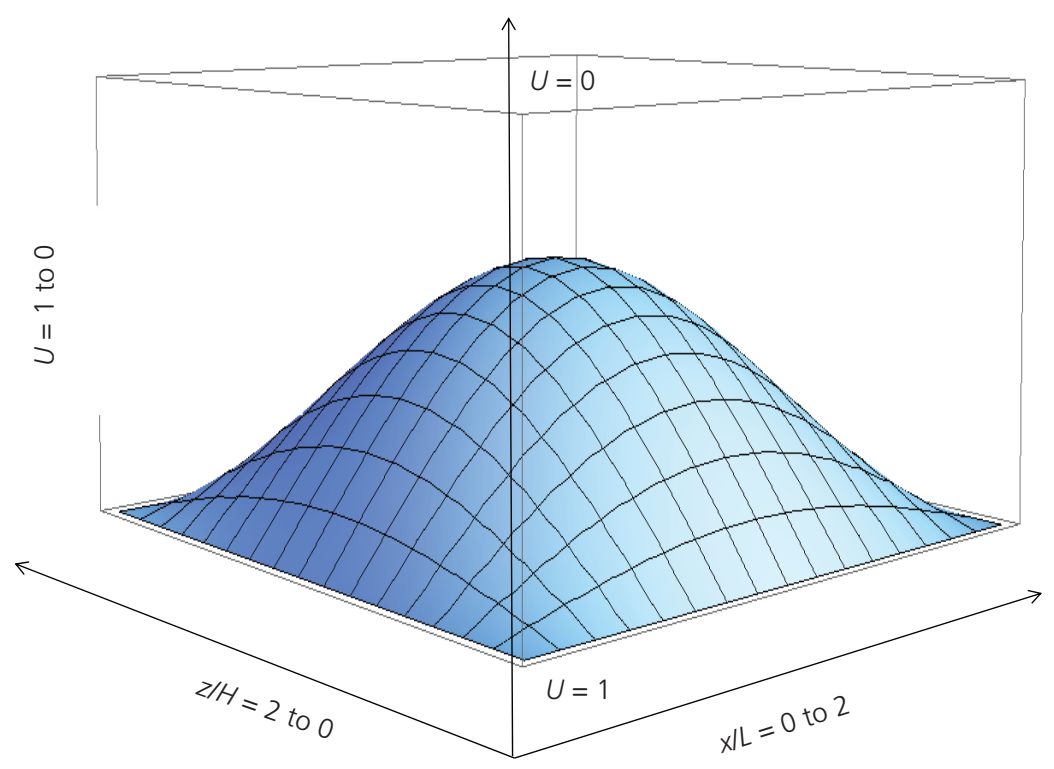

(b)

Figure 9. (a) Isometric representation of $U$ (at $r=0$ and $T V=0 \cdot 2$ )

from exact $2 \mathrm{D}$ solution as $U_{1 D}=50 \%$. (b) Isometric representation of $U$ (at $r=1$ and $T V=0.2$ ) from exact 2D solution as $U_{2 D}=76 \%$. 
exact solutions to a variety of drainage situations and shapes captured by a parameter ( $r=0,1$ and 2 as the order of tensor) estimated from rock mass characteristics, drainage features and extendible to $1 \mathrm{D}$ as well as 3D drainage conditions for gouge amid permeating rock masses. Instead of the parameter (' $r$ '), the discussers use another parameter $(\lambda)$ to describe $1 \mathrm{D}$ to $3 \mathrm{D}$ conditions, which can be numerically related to ' $r$ ' as shown in Table 14. A wide-ranging approximation of primary consolidation $U_{p}$ can be made for varying values of ' $r$ ' as shown in Figure 10.

\section{Deformability and estimating stresses amid permeating rock masses}

The coefficient of consolidation is a product of two tensorial quantities, namely permeability (Bai et al., 1999; Kubik, 1979; Liakopoulos, 1965; Oda, 1985) per unit density and deformability (Trivedi, 2013; Zhang, 2010), which are functions of fracture density, joint and gouge parameters included in $J_{f g}$, and a hardening parameter $C_{h} . J_{f g}$ is a modified joint factor that considers the occurrence of varied engineering possibilities amid rock masses in the range of consolidation pressure. Because of compression of the gouge, the rock mass can undergo significant volume change (Trivedi, 2010) with drainage and shear. The dependence of deformability on $J_{f g}$ and a hardening parameter $C_{h}$ is shown in
Figures 11(a) and 11(b) using some field and numerical data. The average deformability of rock masses is obtained using joint and gouge parameters included in $J_{f g}$, and a hardening parameter $C_{h} . E_{m r}$ is a ratio of deformation modulus of rock mass to the intact rock such that $E_{m r}=\exp \left(C_{h} J_{f g}\right)$. The hardening parameter evolves from the plasticity parameter and initial isotropic pressure. The hardening parameter depends upon plasticity parameter $\alpha_{p}$ and initial isotropic pressure such that $C_{h}=\kappa\left[\left(p_{i} / \sigma_{r}\right)^{\eta}\right]$. The values of the constants $\kappa$ and $\eta$ depend upon $\alpha_{p}$ (Trivedi, 2013).

The in situ geo-technical explorations allow us to capture some values of $E_{m r}$ and $J_{f g}$. Using values of $E_{m r}$ and $J_{f g}$ in Figure 11(a), a value of $C_{h}$ can be found. Figure 11(a) shows estimates of deformation modulus of rock masses interpreted from the field data of Chun et al. (2009). The geo-technical investigations also provide us with information to interpret a plasticity parameter $\alpha_{p}$. Using values of $C_{h}$ and $\alpha_{p}$ in Figure 11(b), a value of initial isotropic pressure amid rock masses can be obtained.

Under the varied pressure conditions of gouge amid rock masses as described by the authors, the deformation and velocity fields (namely, $\delta$ - $\sigma^{\prime}$ against $\delta$ - $\mathrm{d} \sigma^{\prime} / \mathrm{d} \delta$ and $U$ against $\log _{10}(\mathrm{~d} U / \mathrm{d} T)$, respectively) do not remain coaxial, hence precise determination of in situ stresses may remain elusive by the said technique as proposed by the discusser.

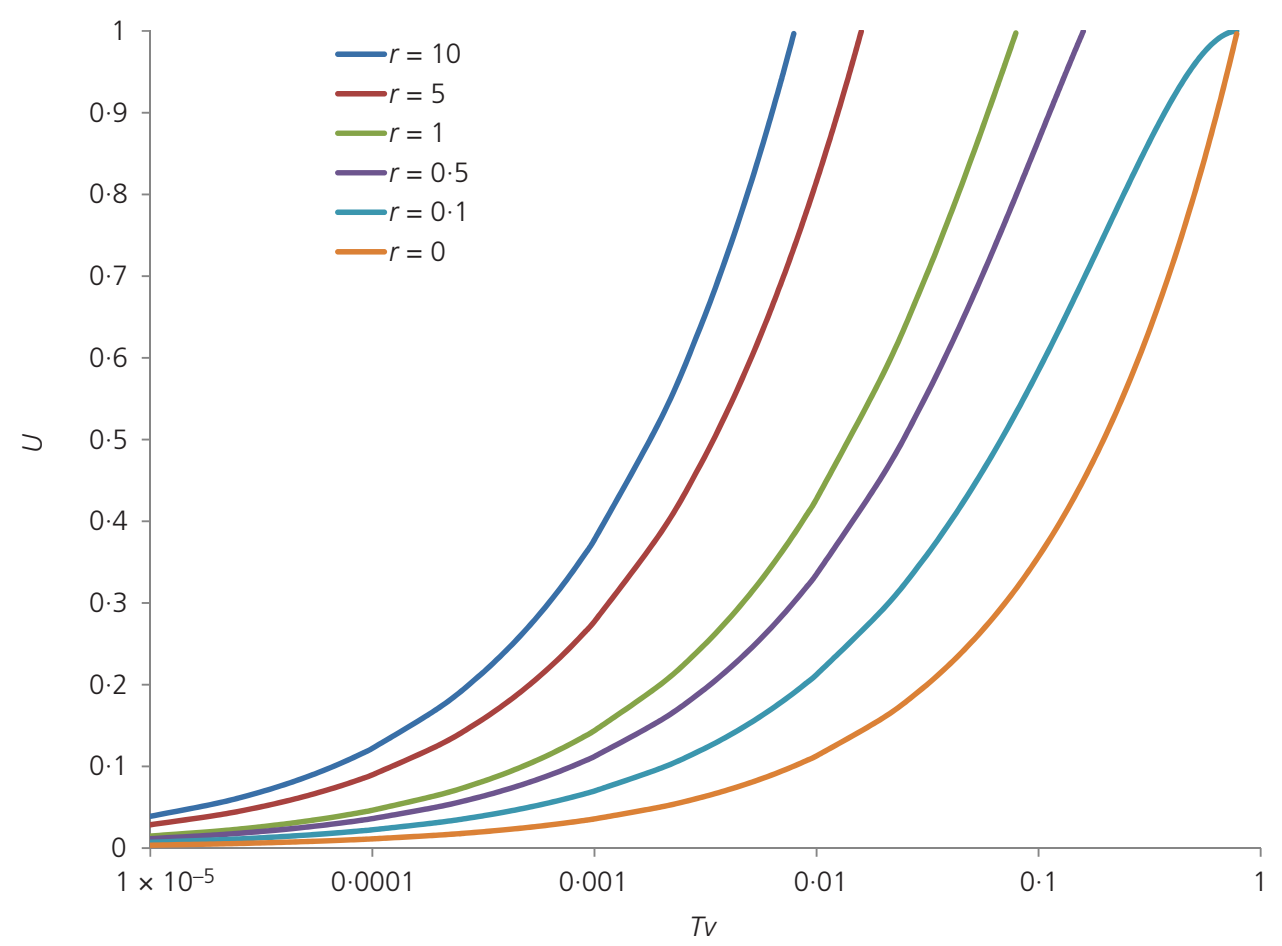

Figure 10. Trajectory of primary consolidation $(r=0-10)$ in approximate solution (derived from the exact 2D solution) in relation to the 1D (as $r=0), 2 \mathrm{D}$ (as $r=1)$ and 3D (as $r=2$ ) consolidation and modified initial convexities 


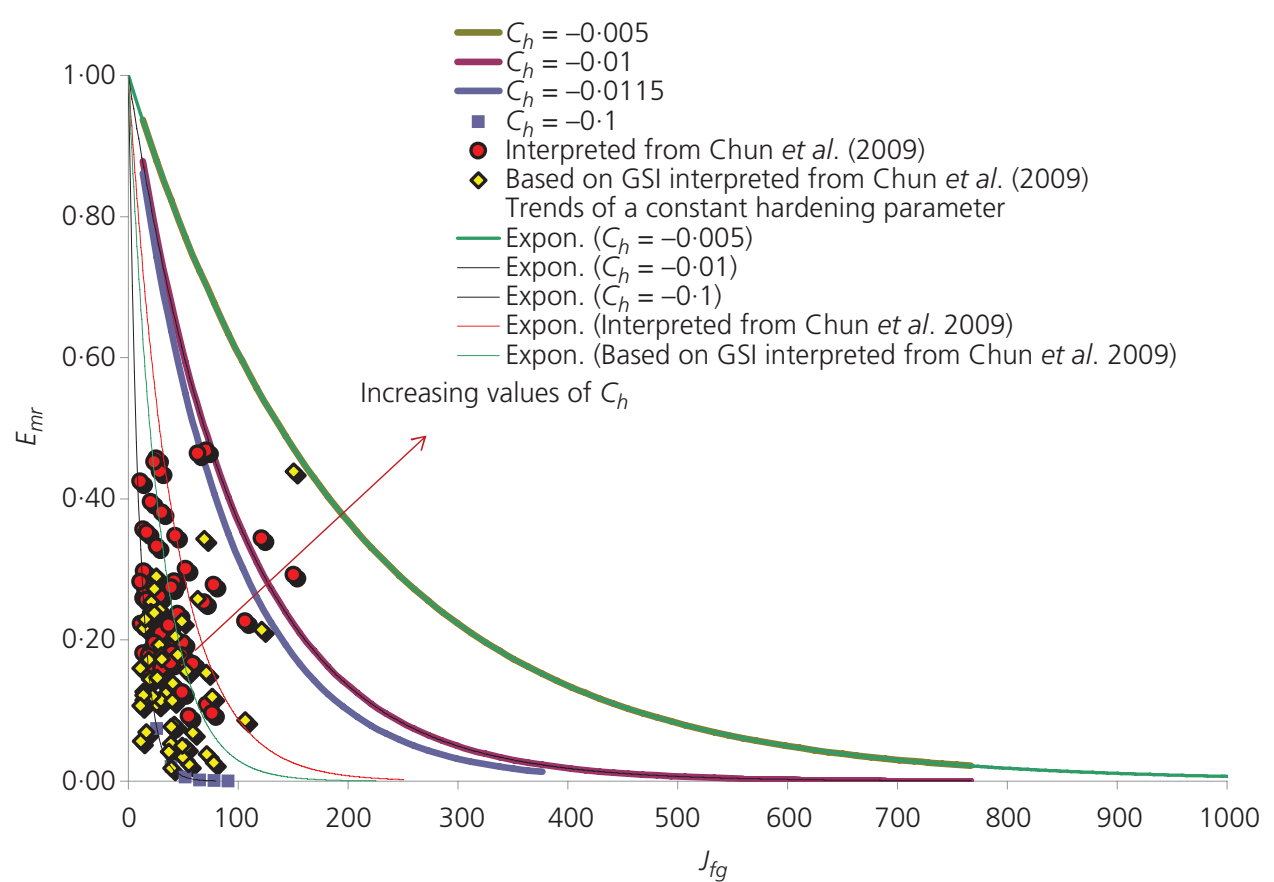

(a)

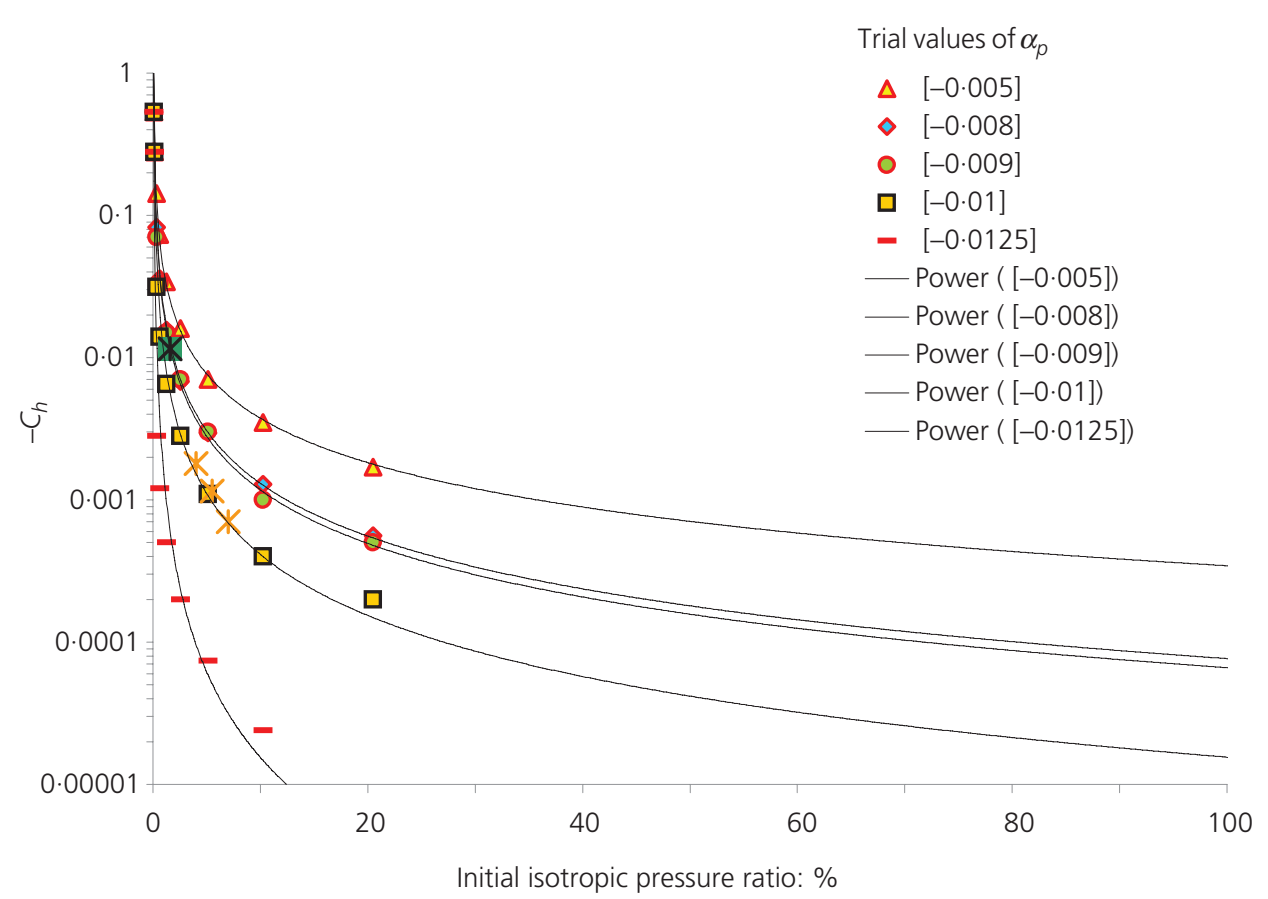

(b)

Figure 11. (a) Estimation of deformability of rock masses using joint and gouge parameters included in $J_{f g}$, and a hardening parameter $C_{h}$. $E_{m r}$ represents a ratio of deformation modulus of rock mass to the intact rock. The hardening parameter depends upon the plasticity parameter and initial isotropic pressure such that $E_{m r}=\exp \left(C_{h} J_{f g}\right)$. (b) Relationship of the hardening parameter $C_{h}$ and initial isotropic pressure ratio; the hardening parameter depends upon plasticity parameter $\alpha_{p}$ and initial isotropic pressure.
The hardening parameter depends upon initial plasticity and initial isotropic pressure such that $C_{h}=\kappa\left[\left(p_{i} / \sigma_{r}\right)^{\eta}\right]$. The values of the constants $\kappa$ and $\eta$ depend upon $\alpha_{p}$. $p_{i} / \sigma_{r}$ is a ratio of initial isotropic pressure and uniaxial compressive strength of intact rock. The plasticity parameter is such that $\sigma_{m r}=\exp \left(\alpha_{p} J_{f g}^{p}\right)$. $J_{f g}^{p}$ is a modified joint factor at plastic failure. $\sigma_{m r}$ represents a ratio of compressive strength of rock mass to the intact rock. 
Nevertheless, the discussers have made an interesting contribution with reference to few presumably coaxial experimental observations; hence, there is a need to explore deformation and velocity fields of consolidating clayey gouge amid permeating rock masses for varied coaxial and non-coaxial deformations.

\section{REFERENCES}

Bai M, Meng F, Elsworth D and Roegiers JC (1999) Analysis of stress-dependent permeability in non-orthogonal flow and deformation fields. Rock Mechanics and Rock Engineering 32(3): 195-219.

Biot MA (1941) General theory of three-dimensional consolidation. Journal of Applied Physics 12(2): 155-164.

Carillo N (1942) Simple two and three dimensional cases in the theory of consolidation of soils. Journal of Mathematical Physics 21(1): 11-18.

Chun BS, Ryu WR, Sagong M and Do JN (2009) Indirect estimation of the rock deformation modulus based on polynomial and multiple regression analyses of the RMR system. International Journal of Rock Mechanics and Mining Science \& Geomechanics Abstracts 46(3): 649-658.

Davis EH and Raymond GP (1965) A non-linear theory of consolidation. Geotechnique 15(2): 161-173.

de Boer R (2000) Contemporary progress in porous media theory. Applied Mechanics Reviews 53(12): 323-370.

de Boer R (2005) The Engineer and the Scandal: A Piece of Science History. Springer, Berlin, Heidelberg, Germany.

Di Francesco R (2011) Exact solutions of two-dimensional and tri-dimensional consolidation equations. Physics.Geo. Ph.arXiv:1103.6084 (1): 1-8.

Kubik J (1979) Permeability tensor and porosity of materials with rectilinear channels. Bull Acad Polon Sci Ser Techn 27: 445-453.

Kubik IJ and Sawczuk IA (1983) A theory of anisotropic consolidation. Ingenieur-Archiv 53(2): 133-143.

Liakopoulos AC (1965) Darcy's coefficient of permeability as symmetric tensor of second rank. Hydrological Sciences Journal 10(3): 41-48.

Newman AB (1931) The drying of porous solids: Diffusion calculations. Trans. AIChE 27: 310-333.

Oda M (1985) Permeability tensor for discontinuous rock masses. Geotechnique 35(4): 483-495.

Scott RF (1963) Principles of Soil Mechanics. Addison-Wesley, London, UK.

Singh KK, Singh DN and Ranjith PG (2013) Simulating flow through fractures in a rock mass using analog material. International Journal of Geomechanics 14(1): 8-19.

Terzaghi K (1923) Mathematisch-naturewissenschaftliche Klasse, Akademie der Wissenschaften in Wien, Sitzungsberichte, Part Iia. 132(3/4): 125-138.
Terzaghi K (1925) Erdbaumechanik auf Bodenphysikalischer Grundlage. F. Deuticke, Vienna, Austria.

Tewatia SK (1998) Evaluation of true $C_{v}$ and instantaneous $C_{v}$, and isolation of secondary consolidation. American Society for Testing and Materials, Geotechnical Testing Journal 21(2): 102-108.

Tewatia SK (2010) Time Dependent Behavior of Clayey Soils. PhD thesis, Department of Civil Engineering, Delhi College of Engineering, Delhi University, India.

Tewatia SK (2013a) Trend of settlement in primary and secondary consolidations. Geomechanics and Geoengineering: An International Journal 8(2): 125-134.

Tewatia SK (2013b) Equation of 3D consolidation in Cartesian co-ordinates. International Journal of Geotechnical Engineering 7(1): 105-108.

Tewatia SK, Dhawan AK, Venkatachalam K and Bose PR (2006) An alternative to a 3D crack monitor - 4 Pin Algorithm. American Society for Testing and Materials, Journal of Testing and Evaluation 34(5): 1-3.

Tewatia SK, Bose PR, Sridharan A and Rath S (2007) Stress induced time dependent behavior of clayey soils. Geotechnical and Geological Engineering Journal 25(2): 239-255.

Tewatia SK, Bose PR and Sridharan A (2013a) Fastest rapid loading methods of vertical and radial consolidations. International Journal of Geomechanics, ASCE 13(4): 332-339.

Tewatia SK, Rath S, Huat BK and Tewatia K (2013b) U-Chart Method for radial and 3D consolidation. Ground Improvement, Proceedings of the Institution of Civil Engineers London 166(GI-1): 1-8.

Tewatia SK, Bose PR and Sridharan A (2014) Closure to 'Fastest rapid loading methods of vertical and radial consolidations.' International Journal of Geomechanics, ASCE 13(4): 332-339 in press.

Trivedi A (2010) Strength and dilatancy of jointed rocks with granular fill. Acta Geotechnica 5(1): 15-31.

Trivedi A (2013) Estimating in situ deformation of rock masses using a hardening parameter and RQD. International Journal of Geomechanics 13(4): 348-364.

Trivedi A, Banik T, Sukumar T et al. (2014) Consolidation of clayey gouge amid permeating rock masses. Environmental Geotechnics, http://dx.doi.org/10.1680/envgeo.13.00043.

Zhang L (2010) Method for estimating the deformability of heavily jointed rock. Journal of Geotechnical and Geoenvironmental Engineering 136(9): 1242-1250. 